\title{
Alarm symptoms in early diagnosis of cancer in primary care: cohort study using General Practice Research Database
}

\author{
Roger Jones, Wolfson professor of general practice, ${ }^{1}$ Radoslav Latinovic, database manager, ${ }^{2}$ \\ Judith Charlton, research assistant, ${ }^{2}$ Martin C Gulliford senior lecturer in public health ${ }^{2}$
}

Department of General Practice and Primary Care, Division of Health and Social Care Research, King's College London School of Medicine at Guy's, King's College and St Thomas' Hospitals, London SE1 6SP

${ }^{2}$ Department of Public Health Sciences, Division of Health and Social Care Research, King's College London School of Medicine at Guy's, King's College and St Thomas' Hospitals, London SE1 3QD

Correspondence to: $\mathrm{R}$ Jones roger.jones@kcl.ac.uk

doi: 10.1136/bmj.39171.637106.AE

\section{ABSTRACT}

Objective To evaluate the association between alarm symptoms and the subsequent diagnosis of cancer in a large population based study in primary care.

Design Cohort study.

Setting UK General Practice Research Database.

Patients 762325 patients aged 15 years and older, registered with 128 general practices between 1994 and 2000. First occurrences of haematuria, haemoptysis, dysphagia, and rectal bleeding were identified in patients with no previous cancer diagnosis..

Main outcome measure Positive predictive value of first occurrence of haematuria, haemoptysis, dysphagia, or rectal bleeding for diagnoses of neoplasms of the urinary tract, respiratory tract, oesophagus, or colon and rectum during three years after symptom onset. Likelihood ratio and sensitivity were also estimated.

Results 11108 first occurrences of haematuria were associated with 472 new diagnoses of urinary tract cancers in men and 162 in women, giving overall three year positive predictive values of $7.4 \%$ (95\% confidence interval $6.8 \%$ to $8.1 \%$ ) in men and $3.4 \%$ (2.9\% to $4.0 \%)$ in women. After 4812 new episodes of haemoptysis, 220 diagnoses of respiratory tract cancer were made in men (positive predictive value $7.5 \%, 6.6 \%$ to $8.5 \%$ ) and 81 in women (4.3\%, 3.4\% to 5.3\%). After 5999 new diagnoses of dysphagia, 150 diagnoses of oesophageal cancer were made in men (positive predictive value $5.7 \%, 4.9 \%$ to $6.7 \%$ ) and 81 in women (2.4\%, 1.9 to $3.0 \%)$. After 15289 episodes of rectal bleeding, 184 diagnoses of colorectal cancer were made in men (positive predictive value $2.4 \%$, $2.1 \%$ to $2.8 \%$ ) and 154 in women (2.0\%, $1.7 \%$ to $2.3 \%$ ). Predictive values increased with age and were strikingly high, for example, in men with haemoptysis aged 75-84 $(17.1 \%, 13.5 \%$ to $21.1 \%)$ and in men with dysphagia aged $65-74$ (9.0\%, $6.8 \%$ to $11.7 \%)$.

Conclusion New onset of alarm symptoms is associated with an increased likelihood of a diagnosis of cancer, especially in men and in people aged over 65 . These data provide support for the early evaluation of alarm symptoms in an attempt to identify underlying cancers at an earlier and more amenable stage.

\section{INTRODUCTION}

More than $80 \%$ of clinical care in the United Kingdom is delivered in general practice and primary care; some general practitioners refer less than $5 \%$ of their patients each year for specialist opinions and hospital investigations. ${ }^{12}$ Referral from primary to secondary care is often triggered by a general practitioner's awareness of so called "alarm symptoms," features in the clinical presentation that are considered to predict serious, often malignant, disease. For example, guidelines on the identification of alarm symptoms form the core of the "two week rule" for urgent referral of patients suspected of having cancer, ${ }^{34}$ and many clinical practice guidelines specify particular symptoms that mandate urgent investigation or referral. ${ }^{5}$ However, the evidence base for the alarming nature of many alarm symptoms is weak, and general practitioners often use individual approaches to the collection and analysis of data in the course of consultations, ${ }^{1}$ often relying on personal heuristics (which may include questions thought to have high negative predictive value for the presence of serious disease).

However, diagnosis of cancer is relatively rare for the individual general practitioner, whose role may be characterised as marginalising danger, in contrast to that of the specialist, whose task is to marginalise uncertainty. ${ }^{6}$ In other words, general practitioners need to sort out the minority of patients who need urgent attention from the majority who are likely to have self limiting disorders, for which time can be used as a diagnostic and therapeutic tool. ${ }^{7}$

Haematuria - microscopic and macroscopic, with or without pain - is thought to account for approximately four consultations per thousand patients per year in primary care in the UK. The presence of painless, macroscopic haematuria is widely regarded as an alarm symptom suggesting the presence of a urinary tract neoplasm, but little information collected in the primary care setting is available to support this assertion. When Buntinx did a systematic review of published reports in 2000 he was unable to find a single primary care study, and the information on which to base decision making in primary care had been collected in referral centres. ${ }^{8}$ A subsequent study from Buntinx's group, using a Belgian sentinel primary care network, reported an overall positive predictive value of haematuria for urological cancer of $10.3 \%$ and a sensitivity of $59.5 \% .^{9}$ Summerton and colleagues' study of a haematuria clinic emphasised the 
importance of looking in detail at the symptom complex associated with haematuria. ${ }^{10}$ Most recently, Hamilton and colleagues derived a positive predictive value for prostate cancer of haematuria alone of only $1 \%$, and several other symptoms had greater predictive values than haematuria. ${ }^{11}$

Dysphagia is a relatively common problem and is often regarded as an alarm symptom mandating urgent referral, generally for contrast radiology in view of the potential dangers of upper gastrointestinal endoscopy in patients with oesophageal obstruction. However, as in many conditions of interest, the information available to guide decision making is derived largely from secondary care settings. ${ }^{12-14}$ A recent systematic review, which identified 83 relevant studies, described wide variation in the sensitivity and specificity of alarm symptoms for upper gastrointestinal malignancies. ${ }^{15}$

Haemoptysis occurs in up to $40 \%$ of patients with bronchitis, and is also seen in other less serious upper respiratory conditions, but it is an important alarm symptom for the presence of bronchial carcinoma, pulmonary tuberculosis, pulmonary embolism, and other serious cardiovascular problems, as well as systemic diseases and coagulopathies. Unsurprisingly, haemoptysis often leads to specialist referral and the use of investigations, but little information is available on the outcome of hospital referrals for haemoptysis and even fewer data are available to guide cost effective decision making in primary care. ${ }^{16-18}$ The most recent publication by Hamilton and colleagues, a population based case-control study, found generally low positive predictive values for symptoms associated with lung cancer except for haemoptysis, with a positive predictive value of haemoptysis alone of $2.4 \%$, but with much higher positive predictive values when haemoptysis was accompanied by other symptoms such as dyspnoea, weight loss, and anorexia. ${ }^{19}$

Rectal bleeding is a common symptom; community surveys indicate that between $7 \%$ and $16 \%$ of the Western adult population report rectal bleeding in a 6-12 month period and that blood is mixed with stool in up to $30 \%$ of cases. ${ }^{19}$ Rectal bleeding is reported by people over the age of 50 less often than in younger patients $(27 \%$ versus $12 \%)$. A minority of people with rectal bleeding consult a physician, and although reasons for consultation may include worry about serious disease, anxiety about an adverse diagnosis is also likely to play a part. Because rectal bleeding is such a well recognised alarm symptom, patients who present with this condition are likely to be referred for lower bowel endoscopy or a specialist opinion after evaluation, including rectal examination, by the primary care physician. However, given the relative infrequency of a diagnosis of malignant or serious inflammatory disease, guidance is needed to help primary care physicians to select patients with rectal bleeding for whom urgent investigation or referral is most appropriate. ${ }^{20-24}$ Few epidemiological data are available to provide an evidence base for these decisions. Buntinx's group found a range of age dependent positive predictive values of rectal bleeding for colorectal cancer in their sentinel network study, ${ }^{25}$ and Lawrenson and colleagues, using the General Practice Research Database, reported an overall positive predictive value for colorectal cancer of $6 \%$ in men and $3.5 \%$ in women. ${ }^{26}$

The General Practice Research Database provides a valuable resource with which to improve our understanding of the significance of these symptoms and of their predictive value for serious disease. It is the world's largest primary care database, containing detailed clinical and healthcare information representing around 13 million patient years, contributed to by several hundred representative general practices in the UK. The structure, utility, and validity of the database and the data that can be extracted from it have been extensively described, and good evidence exists for the comprehensiveness and accuracy of the data. ${ }^{2728}$ In this study, we set out to determine the incidence of so called alarm symptoms, and the association between these symptoms and subsequent diagnosis of neoplasms, by using a retrospective cohort design. For each alarm symptom, we specifically aimed to estimate the proportion of patients with alarm symptoms who were later diagnosed with cancer, or positive predictive value; the proportion of patients diagnosed as having cancer who previously reported the symptom (that is, the sensitivity of the symptom for detecting cancer); and the likelihood ratio of a diagnosis of cancer associated with the symptom.

\section{METHODS}

\section{Practice and patient selection}

We selected all 128 general practices that provided data of a sufficient standard from 1 January 1994 to 31 December 2000 and which provided exclusively Read coded data. We selected all 923605 patients who were registered with these practices between 1 January and 31 December 1994 and were aged 100 years or less in 1994. From these, we identified patients whose first ever recorded occurrence of each alarm symptom (haematuria, haemoptysis, dysphagia, or rectal bleeding) was after 31 December 1994 and who had not previously been diagnosed as having any cancer. The diagnostic codes used are available from the authors.

We then evaluated each patient's record for new occurrences of associated cancers. For haematuria, we evaluated urinary tract neoplasms, including neoplasms of the urethra, bladder, ureter, and kidney but excluding neoplasms of the prostate and other reproductive organs; for dysphagia, we evaluated oesophageal neoplasms only; for haemoptysis, we evaluated respiratory tract neoplasms; and for rectal bleeding, we evaluated colorectal neoplasms. We did this by first identifying all patients who ever had symptoms recorded for haematuria, haemoptysis, dysphagia, or rectal bleeding or who were diagnosed as having neoplasms of the urinary tract, respiratory tract, oesophagus, or colon and rectum.

We then excluded those patients whose date of first symptom or first relevant diagnosis of cancer was before 1 January 1995. In order to include only those 
patients who were previously free from cancer, we excluded all patients with a diagnosis of any other cancer than the ones of interest before the date of the first recorded symptom or before the index cancer diagnosis date if the related symptom was not recorded. In secondary analyses, we also evaluated whether the incidence of neoplasms other than those that we prespecified was increased after the occurrence of alarm symptoms.

\section{Analysis}

To obtain information on the underlying incidence of cancer and the value of symptoms for detecting cancer, we set out to estimate, for each alarm symptom-outcome pair, the incidence of new alarm symptoms by sex in patients not previously diagnosed as having cancer; in patients with new occurrences of alarm symptoms, the proportions with related cancer outcomes diagnosed over time (positive predictive value); the incidence of outcome cancer by sex; and the proportions of cancer patients who had previous alarm symptoms in defined preceding time intervals (sensitivity).

In patients who presented with alarm symptoms, we determined whether a first diagnosis of the associated neoplasm occurred in successive quarters up to five years. As most cancer diagnoses occurred within three years of the first symptom, we evaluated the proportion of patients with symptoms who were diagnosed as having cancer in the next three years as the positive predictive value for the symptom. We calculated exact binomial confidence intervals. We compared the observed number of new diagnoses of associated cancers in patients with alarm symptoms with the number expected if the age and sex specific cancer incidence rates for the study population applied to the sample of patients who had the symptom of interest. We compared the observed and expected numbers of cancer occurrences by estimating a standardised incidence ratio with $95 \%$ confidence intervals estimated from the Poisson distribution. For a rare disease in a defined

\begin{tabular}{|c|c|c|c|c|}
\hline \multirow[b]{2}{*}{ Site } & \multicolumn{2}{|r|}{ Symptom } & \multicolumn{2}{|r|}{ Neoplasm } \\
\hline & Cases & $\begin{array}{l}\text { Incidence per } 100000 \\
\text { person years }(95 \% \mathrm{Cl})\end{array}$ & Cases & $\begin{array}{c}\text { Incidence per } 100000 \text { person } \\
\text { years }(95 \% \mathrm{Cl})\end{array}$ \\
\hline Urinary tract & \multicolumn{2}{|r|}{ Haematuria } & \multicolumn{2}{|r|}{ Urinary tract neoplasms } \\
\hline Men & 6411 & 285.1 (278.1 to 292.2 ) & 883 & 35.6 (33.2 to 38.0$)$ \\
\hline Women & 4727 & 206.0 (199.8 to 212.2) & 330 & 10.5 (9.3 to 11.7$)$ \\
\hline Respiratory tract & \multicolumn{2}{|r|}{ Haemoptysis } & \multicolumn{2}{|c|}{ Respiratory tract neoplasms } \\
\hline Men & 2938 & 138.5 (133.4 to 143.6$)$ & 1135 & $45.0(42.3$ to 47.6$)$ \\
\hline Women & 1884 & 83.6 (79.7 to 87.6$)$ & 636 & 21.1 (19.3 to 22.8 ) \\
\hline Oesophagus & \multicolumn{2}{|r|}{ Dysphagia } & \multicolumn{2}{|c|}{ Oesophageal neoplasms } \\
\hline Men & 2631 & 117.1 (112.6 to 121.7$)$ & 282 & $11.6(10.2$ to 13.0$)$ \\
\hline Women & 3372 & 130.8 (126.1 to 135.6$)$ & 158 & $4.4(3.6$ to 5.1$)$ \\
\hline Rectum and colon & \multicolumn{2}{|r|}{ Rectal bleeding } & \multicolumn{2}{|r|}{ Colorectal neoplasms } \\
\hline Men & 7533 & 361.2 (353.0 to 369.5 ) & 739 & $30.2(27.9$ to 32.4$)$ \\
\hline Women & 7781 & 354.9 (346.6 to 363.2$)$ & 644 & 19.4 (17.8 to 21.0 ) \\
\hline
\end{tabular}

European standard population used as reference.
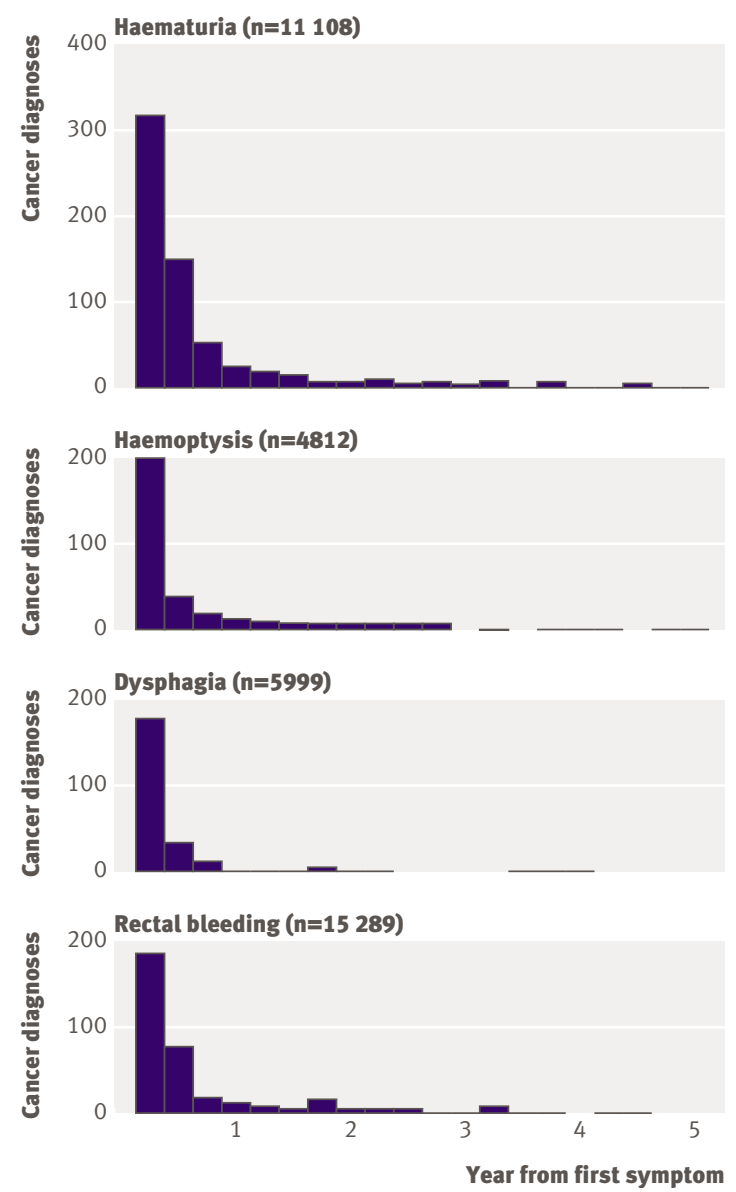

Distribution of related cancer diagnoses by quarter after onset of alarm symptoms

population, the ratio of observed to expected number of cancer diagnoses provides an estimate of the ratio of post-test to pretest odds of a cancer diagnosis. The standardised incidence ratio therefore provides an estimate of the likelihood ratio of a positive test.

To evaluate the sensitivity of each alarm symptom as a test for cancer, we evaluated only those patients whose first cancer diagnosis was in 1999 or 2000 to ensure that each patient had at least five years of records before the cancer diagnosis date. For each patient with a cancer diagnosis, we determined whether a record of the relevant alarm symptom existed during the preceding three years.

\section{RESULTS}

Our population consisted of 923605 eligible patients registered with 128 practices in 1994, of whom 762325 were aged 15 years or older. We evaluated first occurrences of alarm symptoms in patients with no previous diagnosis of cancer. We found 11138 first occurrences of haematuria, 4822 of haemoptysis, 6003 of dysphagia, and 15314 of rectal bleeding in patients aged 15 years or older between 1 January 1995 and 31 December 2000. Table 1 shows the age and sex standardised incidence rates for alarm symptoms and their 
associated cancers in the population aged 15 years and over, using the European standard population for reference. Each group of neoplasms was more frequent in men than in women; respiratory tract neoplasms were the most frequent, and oesophageal neoplasms were the rarest. First episodes of alarm symptoms were generally between 10 and 20 times more frequent than associated neoplasms, but this was not so for haemoptysis, which was only three times more frequent than the incidence of respiratory neoplasms. The mean age at first symptom was 58.5 (SD 18.9) years for haematuria, 61.6 (18.0) years for dysphagia, 54.5 (19.4) years for haemoptysis, and 52.5 (18.8) years for rectal bleeding. Table 2 shows age specific incidence rates of symptoms.

In the next stage of the analysis, we omitted data for patients with incomplete dates for their first symptom: we excluded 30 with haematuria, 10 with haemoptysis,
4 with dysphagia, and 25 with rectal bleeding. The figure shows the distribution of related cancer diagnoses by quarter after the first recorded alarm symptom. Diagnoses of cancer were most often made in the first three months after the onset of alarm symptoms; very few diagnoses of cancer were made later than three years after symptom onset. Table 3 gives the observed numbers of new occurrences of related cancers in the first six months and three years after symptom onset, with positive predictive values and likelihood ratios for each symptom. Haematuria and haemoptysis had the highest predictive values for cancer, followed by dysphagia and rectal bleeding. In the fourth and fifth years of study, the small number of observed occurrences of cancer were similar to the number expected from background incidence rates (fig).

In secondary analyses, we searched for diagnoses of cancer other than those that we had pre-specified. After

\begin{tabular}{|c|c|c|c|c|}
\hline \multirow[b]{2}{*}{$\begin{array}{l}\text { Age group } \\
\text { (years) }\end{array}$} & \multicolumn{2}{|r|}{ Women } & \multicolumn{2}{|r|}{ Men } \\
\hline & $\begin{array}{l}\text { No with } \\
\text { symptom }\end{array}$ & $\begin{array}{c}\text { Incidence }(95 \% \mathrm{Cl}) \text { per } 100000 \text { person } \\
\text { years }\end{array}$ & $\begin{array}{l}\text { No with } \\
\text { symptom }\end{array}$ & Incidence $(95 \% \mathrm{Cl})$ per 100000 person years \\
\hline \multicolumn{5}{|l|}{ Haematuria } \\
\hline $15-24$ & 359 & 144.7 (129.7 to 159.7$)$ & 288 & 103.1 (91.2 to 115.0$)$ \\
\hline $25-34$ & 434 & 142.4 (129.0 to 155.8$)$ & 413 & 127.7 (115.4 to 140.0$)$ \\
\hline $35-44$ & 571 & $161.3(148.1$ to 174.5$)$ & 618 & $172.2(158.6$ to 185.7$)$ \\
\hline $45-54$ & 745 & 204.7 (190.0 to 219.4$)$ & 899 & 243.0 (227.1 to 258.9$)$ \\
\hline $55-64$ & 790 & 280.7 (261.1 to 300.2$)$ & 1109 & $392.0(368.9$ to 415.0$)$ \\
\hline $65-74$ & 847 & 337.7 (315.0 to 360.5$)$ & 1526 & $690.1(655.5$ to 724.7$)$ \\
\hline $75-84$ & 688 & 364.1 (336.9 to 391.3$)$ & 1200 & 967.7 (913.0 to 1022.5$)$ \\
\hline$\geq 85$ & 293 & $380.6(337.0$ to 424.1$)$ & 358 & 1152.7 (1033.3 to 1272.2$)$ \\
\hline \multicolumn{5}{|c|}{ Haemoptysis } \\
\hline $15-24$ & 141 & $56.8(47.5$ to 66.2$)$ & 294 & 105.2 (93.2 to 117.3$)$ \\
\hline $25-34$ & 182 & 59.7 (51.0 to 68.4) & 299 & 92.5 (82.0 to 103.0$)$ \\
\hline $35-44$ & 230 & $65.0(56.6$ to 73.4$)$ & 365 & 101.7 (91.2 to 112.1$)$ \\
\hline $45-54$ & 272 & 74.7 (65.9 to 83.6$)$ & 427 & 115.4 (104.5 to 126.4$)$ \\
\hline $55-64$ & 364 & 129.3 (116.0 to 142.6$)$ & 515 & 182.0 (166.3 to 197.7$)$ \\
\hline $65-74$ & 360 & 143.5 (128.7 to 158.4$)$ & 552 & 249.6 (228.8 to 270.5$)$ \\
\hline $75-84$ & 258 & 136.5 (119.9 to 153.2$)$ & 393 & 316.9 (285.6 to 348.3$)$ \\
\hline$\geq 85$ & 77 & $100.0(77.7$ to 122.3$)$ & 93 & 299.5 (238.6 to 360.3 ) \\
\hline \multicolumn{5}{|l|}{ Dysphagia } \\
\hline $15-24$ & 87 & 35.1 (27.7 to 42.4$)$ & 94 & $33.6(26.8$ to 40.5$)$ \\
\hline $25-34$ & 181 & $59.4(50.7$ to 68.0$)$ & 141 & $43.6(36.4$ to 50.8$)$ \\
\hline $35-44$ & 374 & 105.7 (94.9 to 116.4$)$ & 247 & $68.8(60.2$ to 77.4$)$ \\
\hline $45-54$ & 521 & 143.2 (130.9 to 155.5$)$ & 423 & 114.3 (103.4 to 125.2$)$ \\
\hline $55-64$ & 522 & 185.4 (169.5 to 201.4$)$ & 518 & 183.1 (167.3 to 198.8$)$ \\
\hline $65-74$ & 659 & 262.8 (242.7 to 282.8$)$ & 577 & 260.9 (239.7 to 282.2$)$ \\
\hline $75-84$ & 645 & 341.3 (315.0 to 367.7 ) & 476 & 383.9 (349.4 to 418.3$)$ \\
\hline$\geq 85$ & 383 & 497.4 (447.6 to 547.3$)$ & 155 & $499.1(420.5$ to 577.7$)$ \\
\hline \multicolumn{5}{|c|}{ Rectal bleeding } \\
\hline $15-24$ & 682 & 274.9 (254.2 to 295.5$)$ & 473 & 169.3 (154.0 to 184.6$)$ \\
\hline $25-34$ & 1019 & 334.3 (313.8 to 354.8 ) & 917 & 283.6 (265.2 to 301.9$)$ \\
\hline $35-44$ & 1085 & 306.5 (288.3 to 324.7$)$ & 1314 & 366.0 (346.2 to 385.8$)$ \\
\hline $45-54$ & 1271 & 349.2 (330.0 to 368.4 ) & 1543 & 417.1 (396.3 to 437.9 ) \\
\hline $55-64$ & 1201 & $426.7(402.5$ to 450.8$)$ & 1302 & $460.2(435.2$ to 485.2$)$ \\
\hline $65-74$ & 1161 & 462.9 (436.3 to 489.5$)$ & 1191 & 538.6 (508.0 to 569.2$)$ \\
\hline $75-84$ & 932 & 493.2 (461.6 to 524.9$)$ & 636 & 512.9 (473.0 to 552.8$)$ \\
\hline$\geq 85$ & 430 & 558.5 (505.7 to 611.3$)$ & 157 & 505.5 ( 426.5 to 584.6$)$ \\
\hline
\end{tabular}


haematuria, inclusion of cancers of the reproductive organs yielded 21 additional cancers in women and 158 cancers in men, mostly cancers of the prostate. Inclusion of these cancers in the analysis would give a positive predictive value of $3.9 \%$ in women and $9.9 \%$ in men. After dysphagia, inclusion of gastric cancers yielded 17 additional cancer diagnoses in women and 30 in men. Inclusion of these cancers gave positive predictive values of $5.2 \%$ in women and $6.9 \%$ in men. Estimates based on the pre-specified cancers may be thus conservative for these symptoms. Extending the diagnostic criteria yielded only six additional cancers after haemoptysis and two additional cancers after rectal bleeding. Table 4 shows the predictive value of each alarm symptom for cancer over the next three years in six age groups, emphasising the substantial effects of both age and sex.

Table 5 shows the proportion of patients who received a diagnosis of cancer in either 1999 or 2000 and who had been recorded as having an alarm symptom in the preceding three years. Over this preceding three year period, the proportion of patients with urinary tract cancer who had previous haematuria was $58.7 \%$ in men and $51.2 \%$ in women. This represents the sensitivity of the symptom for detecting cancer. The sensitivity of haemoptysis for a diagnosis of respiratory tract cancer was $22.2 \%$ in men and $13.6 \%$ in women. The sensitivity of dysphagia for a diagnosis of oesophageal cancer was
$58.3 \%$ in men and $53.8 \%$ in women, and the sensitivity of rectal bleeding for a diagnosis of rectal cancer was $33.3 \%$ in women and $25.1 \%$ in women.

\section{DISCUSSION}

This study provides estimates for the increased likelihood of diagnosis of a related cancer after the first episode of four common alarm symptoms often encountered in primary care. In the first three months after the first presentation with haematuria, haemoptysis, dysphagia, or rectal bleeding, the likelihood of a diagnosis of cancer was greatly increased. Over three years, the relative increase was highest for oesophageal cancer after dysphagia and lowest for a diagnosis of colorectal cancer after rectal bleeding. The increased likelihood of a diagnosis of cancer remained high during the first year after an alarm symptom but gradually declined over time and was not significantly different from background at five years. This is reflected in the predictive values for cancer that we have derived, which although significant across all age groups are striking in older patients, particularly in men and in patients with haemoptysis and haematuria.

\section{Strengths and limitations}

This study has the strength of a large registered and accurately characterised population, drawn from a large number of general practices. Previous studies

Table 3 | Observed related diagnoses of cancer in first six months and three years after first alarm symptom, positive predictive value, and likelihood ratio for cancer after symptom

\begin{tabular}{|c|c|c|c|c|c|}
\hline & No with symptom & $\begin{array}{c}\text { Cumulative No } \\
\text { of cancer } \\
\text { diagnoses }\end{array}$ & Positive predictive value $(\%)(95 \% \mathrm{Cl})$ & $\begin{array}{l}\text { Expected No of } \\
\text { cancer } \\
\text { diagnoses }\end{array}$ & Likelihood ratio $(95 \% \mathrm{Cl})$ \\
\hline \multicolumn{6}{|c|}{ Six months after first symptom } \\
\hline \multicolumn{6}{|c|}{ Haematuria: } \\
\hline Men & 6385 & 349 & $5.5(4.9$ to 6.1$)$ & 3.1 & $110.9(99.2$ to 122.5$)$ \\
\hline Women & 4723 & 117 & 2.5 (2.1 to 3.0$)$ & 0.5 & 215.3 (176.3 to 254.3$)$ \\
\hline \multicolumn{6}{|c|}{ Haemoptysis: } \\
\hline Men & 2930 & 169 & $5.8(5.0$ to 6.7$)$ & 1.4 & 116.7 (99.1 to 134.3$)$ \\
\hline Women & 1882 & 63 & $3.3(2.6$ to 4.3$)$ & 0.4 & 153.1 (115.3 to 190.8$)$ \\
\hline \multicolumn{6}{|l|}{ Dysphagia: } \\
\hline Men & 2628 & 138 & $5.3(4.4$ to 6.2$)$ & 0.4 & 347.9 (289.9 to 405.9$)$ \\
\hline Women & 3371 & 70 & 2.1 (1.6 to 2.6$)$ & 0.3 & 266.2 (203.8 to 328.5$)$ \\
\hline \multicolumn{6}{|c|}{ Rectal bleeding: } \\
\hline Men & 7523 & 138 & $1.8(1.5$ to 2.2$)$ & 1.8 & $75.3(62.7$ to 87.8$)$ \\
\hline Women & 7766 & 119 & 1.5 (1.3 to 1.8$)$ & 1.5 & $78.1(64.1$ to 92.1$)$ \\
\hline \multicolumn{6}{|c|}{ Three years after first symptom } \\
\hline \multicolumn{6}{|c|}{ Haematuria: } \\
\hline Men & 6385 & 472 & $7.4(6.8$ to 8.1$)$ & 18.9 & $25.0(22.7$ to 27.2$)$ \\
\hline Women & 4723 & 162 & $3.4(2.9$ to 4.0$)$ & 3.3 & 49.7 (42.0 to 57.3$)$ \\
\hline \multicolumn{6}{|c|}{ Haemoptysis: } \\
\hline Men & 2930 & 220 & $7.5(6.6$ to 8.5$)$ & 8.7 & 25.3 (22.0 to 28.7$)$ \\
\hline Women & 1882 & 81 & 4.3 (3.4 to 5.3$)$ & 2.5 & $32.8(25.6$ to 40.0$)$ \\
\hline \multicolumn{6}{|l|}{ Dysphagia: } \\
\hline Men & 2628 & 150 & $5.7(4.9$ to 6.7$)$ & 2.4 & $63.0(52.9$ to 73.1$)$ \\
\hline Women & 3371 & 81 & 2.4 (1.9 to 3.0 ) & 1.6 & $51.3(40.1$ to 62.5$)$ \\
\hline \multicolumn{6}{|c|}{ Rectal bleeding: } \\
\hline Men & 7523 & 184 & 2.4 (2.1 to 2.8 ) & 11.0 & 16.7 (14.3 to 19.1$)$ \\
\hline Women & 7766 & 154 & $2.0(1.7$ to 2.3$)$ & 9.2 & $16.8(14.2$ to 19.5$)$ \\
\hline
\end{tabular}


have evaluated the quality of data in the General Practice Research Database with satisfactory results, ${ }^{2728}$ and the population of patients we have studied is likely to be similar to the general population of the UK and of other Western societies. Diagnoses recorded in the database have been shown to be generally valid, and this may be especially the case for cancer. The incidences we report are broadly similar to those reported from cancer registries, but such comparisons are approximate for several reasons. We derived our denominator data from registered rather than resident populations, and they may be inflated. We have also aggregated diagnostic categories where appropriate and excluded all cases with previous diagnoses of cancer. Our analyses included only well defined groups of associated neoplasms. We acknowledge that alarm symptoms may be caused by other serious conditions, both neoplastic and non-neoplastic, as our secondary analyses showed.

We also acknowledge that greater imprecision is likely in the recording of symptoms than of medical diagnoses, and we do not know how long the symptoms were present before they were first recorded at a general practice consultation. Previous studies have indicated that patients may delay seeking medical advice for recta bleeding, for example, for many months and for many reasons. ${ }^{19}$ In addition, we are not able to accurately characterise the nature of some of these alarm symptoms - in the case of rectal bleeding, for example, whether the blood was fresh and accompanied by pain or was darker, mixed with stool, and painless. Different presentations are likely to carry different pathological implications; Ellis and Thompson found rectal bleeding accompanied by a change in bowel habit, without any peri-anal symptoms, to have a positive predictive value for colorectal cancer of $11.1 \%$ in their study of 319 patients consulting general practitioners about recta bleeding. ${ }^{29}$ Similarly, we are unable to comment on whether the haematuria was painful or painless, whether haemoptysis occurred in the context of a respiratory illness, or whether dysphagia was accompanied by other upper gastrointestinal symptoms or, indeed, whether swallowing difficulties were related to fluids or to solids. Studies by Bruyninckx et al and Summerton et al both emphasised the importance of associated symptoms in patients with haematuria and their propensity to "amplify" the predictive value of a single symptom. $^{910}$

Table 4 | Observed related cancer diagnoses in first three years after first alarm symptom and positive predictive value for cancer by broad age group and sex

\begin{tabular}{|c|c|c|c|c|c|c|}
\hline \multirow[b]{2}{*}{$\begin{array}{l}\text { Age group } \\
\text { (years) }\end{array}$} & \multicolumn{3}{|r|}{ Women } & \multicolumn{3}{|r|}{ Men } \\
\hline & Cancers & Total* & Positive predictive value (\%) $(95 \% \mathrm{Cl})$ & Cancers & Total* & $\begin{array}{l}\text { Positive predictive value (\%) }(95 \% \\
\mathrm{Cl})\end{array}$ \\
\hline \multicolumn{7}{|l|}{ Haematuria } \\
\hline$\ll 45$ & 3 & 1361 & $0.22(0.05$ to 0.64$)$ & 13 & 1311 & $0.99(0.53$ to 1.69$)$ \\
\hline $45-54$ & 10 & 745 & 1.34 (0.65 to 2.45$)$ & 39 & 897 & 4.35 (3.11 to 5.90$)$ \\
\hline 55 to 64 & 27 & 790 & $3.42(2.26$ to 4.93$)$ & 94 & 1104 & 8.51 (6.94 to 10.32$)$ \\
\hline 65 to 74 & 50 & 846 & 5.91 (4.42 to 7.72$)$ & 170 & 1517 & 11.21 (9.66 to 12.90$)$ \\
\hline 75 to 84 & 47 & 688 & 6.83 (5.06 to 8.98$)$ & 123 & 1198 & $10.27(8.61$ to 12.13$)$ \\
\hline$\geq 85$ & 25 & 293 & $8.53(5.60$ to 12.3$)$ & 33 & 358 & $9.22(6.43$ to 12.70$)$ \\
\hline \multicolumn{7}{|c|}{ Haemoptysis } \\
\hline$<45$ & 2 & 553 & $0.36(0.04$ to 1.30$)$ & 2 & 954 & 0.21 (0.03 to 7.55$)$ \\
\hline $45-54$ & 5 & 272 & $1.84(0.60$ to 4.24$)$ & 7 & 424 & 1.65 (0.67 to 3.37$)$ \\
\hline 55 to 64 & 15 & 364 & $4.12(2.32$ to 6.71$)$ & 43 & 514 & 8.37 (6.12 to 11.1$)$ \\
\hline 65 to 74 & 30 & 358 & $8.38(5.73$ to 11.8$)$ & 82 & 552 & $14.86(12.0$ to 18.1$)$ \\
\hline 75 to 84 & 27 & 258 & $10.47(7.01$ to 14.9$)$ & 67 & 393 & 17.05 (13.5 to 21.1$)$ \\
\hline$\geq 85$ & 2 & 77 & $2.60(0.32$ to 9.07$)$ & 19 & 93 & 20.43 (12.8 to 30.1$)$ \\
\hline \multicolumn{7}{|l|}{ Dysphagia } \\
\hline$<45$ & 1 & 642 & $0.16(0.00$ to 0.86$)$ & 1 & 482 & $0.21(0.00$ to 1.15$)$ \\
\hline $45-54$ & 3 & 520 & $0.58(0.12$ to 1.68$)$ & 17 & 422 & 4.03 (2.36 to 6.37$)$ \\
\hline 55 to 64 & 10 & 522 & $1.92(0.92$ to 3.49$)$ & 31 & 518 & $5.98(4.10$ to 8.39$)$ \\
\hline 65 to 74 & 25 & 659 & $3.79(2.47$ to 5.55$)$ & 52 & 576 & $9.03(6.82$ to 11.7$)$ \\
\hline 75 to 84 & 26 & 645 & $4.03(2.65$ to 5.85$)$ & 34 & 476 & $7.14(5.00$ to 9.84$)$ \\
\hline$\geq 85$ & 16 & 383 & $4.18(2.41$ to 6.70$)$ & 15 & 154 & $9.74(5.55$ to 15.6$)$ \\
\hline \multicolumn{7}{|c|}{ Rectal bleeding } \\
\hline$<45$ & 6 & 2780 & $0.22(0.08$ to 0.47$)$ & 2 & 2701 & 0.07 (0.01 to 0.27$)$ \\
\hline $45-54$ & 8 & 1270 & $0.63(0.27$ to 1.24$)$ & 24 & 1542 & $1.56(1.00$ to 2.31$)$ \\
\hline 55 to 64 & 33 & 1200 & 2.75 (1.90 to 3.84) & 44 & 1302 & $3.38(2.47$ to 4.51$)$ \\
\hline 65 to 74 & 28 & 1156 & $2.42(1.62$ to 3.48$)$ & 57 & 1188 & $4.80(3.65$ to 6.17$)$ \\
\hline 75 to 84 & 67 & 930 & $7.20(5.63$ to 9.06$)$ & 49 & 633 & $7.74(5.78$ to 10.1$)$ \\
\hline$\geq 85$ & 12 & 430 & 2.79 (1.45 to 4.82$)$ & 8 & 157 & $5.10(2.23$ to 9.79$)$ \\
\hline
\end{tabular}

*Total number of patients in category with alarm symptom. 
Table 5 - Occurrence of alarm symptoms in three years preceding diagnosis of neoplasms for cases diagnosed in 1999 and 2000. Values are cumulative frequencies unless stated otherwise

\begin{tabular}{|c|c|c|c|}
\hline & $\begin{array}{c}\text { Cancers diagnosed in } 1999 \\
\text { or } 2000\end{array}$ & $\begin{array}{l}\text { Alarm symptom in } \\
\text { preceding } 3 \text { years }\end{array}$ & Sensitivity (\%) $(95 \% \mathrm{Cl})$ \\
\hline \multicolumn{4}{|c|}{ Urinary tract neoplasms } \\
\hline Men & 293 & 172 & 58.7 (52.8 to 64.4) \\
\hline Women & 125 & 64 & 51.2 (42.1 to 60.2$)$ \\
\hline \multicolumn{4}{|c|}{ Respiratory tract neoplasms } \\
\hline Men & 302 & 67 & 22.2 (17.6 to 27.3$)$ \\
\hline Women & 169 & 23 & $13.6(8.8$ to 19.7$)$ \\
\hline \multicolumn{4}{|c|}{ Oesophageal neoplasms } \\
\hline Men & 84 & 49 & 58.3 (47.1 to 69.0$)$ \\
\hline Women & 52 & 28 & 53.8 (39.5 to 67.8$)$ \\
\hline \multicolumn{4}{|c|}{ Colorectal neoplasms } \\
\hline Men & 237 & 79 & 33.3 (27.4 to 39.7$)$ \\
\hline Women & 183 & 46 & 25.1 (19.0 to 32.1) \\
\hline
\end{tabular}

\section{Implications}

However, we believe that this new analysis offers additional information on which to base guidance for general practitioners on the management of patients presenting with alarm symptoms, four of which we have studied here. We have shown a very significantly increased risk of cancer being diagnosed in the three to six month period after presentation with an alarm symptom, with different risks attached to different alarm symptoms, different sexes, and different age ranges. The differences in age and sex specific incidence rates for these alarm symptoms are interesting. To some extent, they are likely to reflect the differential prevalence of the various cancers in men and women, but they may also be related to differences in healthcare seeking behaviour in men and women.

For haematuria, the risk of a cancer being diagnosed is greatly increased in the first three to six months after presentation, particularly in younger patients and, in the later years, in middle aged men and older women. Haematuria that is unexplained by urinary tract infection can readily be investigated by careful physical examination and fibreoptic cystoscopy and imaging of the upper renal tract, and our results suggest that these investigations should be done with a minimum of delay in patients in the highest risk groups identified in this study.

Haemoptysis has an unsurprisingly low sensitivity for a respiratory tract malignancy, most likely because

\section{WHAT IS ALREADY KNOWN ON THIS TOPIC}

Alarm symptoms or "red flags" are often used to identify patients whose symptoms need investigation

The evidence for the "alarming" nature of some of these symptoms is weak

\section{WHAT THIS STUDY ADDS}

Likelihood ratios for a diagnosis of cancer after haematuria, haemoptysis, dysphagia, and rectal bleeding are high in the first six months and fall towards unity at around three years Predictive values for a diagnosis of cancer vary according to age, sex, and alarm symptom, and rise with age

The data provide support for the selection of patients presenting with these symptoms in general practice and needing urgent investigation of its frequent association with respiratory tract infection. However, unexplained haemoptysis is associated with a very high risk of a diagnosis of cancer, particularly in the three month period after haemoptysis, suggesting that when haemoptysis is unexplained by respiratory infection or other local factors, imaging studies should be done in a timely fashion to identify or exclude an underlying neoplastic cause.

Dysphagia is also associated with a high rate of diagnosis of oesophageal cancer, particularly in men, in the three to six month period immediately after presentation, suggesting that dysphagia unexplained by nonneoplastic diseases such as reflux oesophagitis should be investigated promptly. Recent guidelines on the management of gastro-oesophageal reflux disease have suggested that only progressive dysphagia should be regarded as an alarm symptom and that dysphagia improves with antisecretory treatment in many reflux patients, ${ }^{2930}$ but our data suggest that progress needs to be monitored over a fairly narrow time frame if early diagnosis is to be facilitated. A recently published systematic review underlines the weakness of data available to guide clinicians on the most appropriate management of patients with dysphagia, ${ }^{31}$ and our data add weight to the recognition of this symptom as being significantly associated with a high risk of a cancer diagnosis in the three month period after presentation. Although database studies are unable to capture the finer details of patients' symptom presentations, they have the major advantage of providing much greater analytical power than clinical studies, such as follow-up of prospective endoscopic series.

Finally, rectal bleeding, a common problem in the general population and a controversial topic in terms of the need for full investigation, is associated with high rates of cancer diagnosis in the 90 day period immediately after presentation. A recent study from general practice in the UK suggested that one in 10 patients presenting with rectal bleeding have colonic neoplasia, and the authors recommended full investigation of all patients with rectal bleeding on the basis of these figures. ${ }^{32}$ Some evidence exists that the characteristics of the bleeding are important in making a decision to investigate urgently, and, because of the ubiquity of rectal bleeding (affecting 10-20\% of the general population each year), our epidemiological data need to be considered in the context of the clinical presentation and the likelihood of the bleeding (painless, dark blood, mixed with stool) being related to a colonic malignancy, although of course all rectal bleeding needs to be investigated by local examination and by digital rectal examination as an absolute minimum. ${ }^{243334}$

\section{Conclusions}

Taken overall, our results provide additional support for the concept of alarm symptoms in primary caresymptoms that are associated with a subsequently greatly elevated risk of serious disease being identified. The association between alarm symptoms and high rates of cancer diagnosis vary somewhat between 
men and women and across different age ranges, and individual alarm symptoms have different sensitivities and specificities for a final diagnosis of cancer. The most striking associations found in our study were between haematuria and urinary tract neoplasia and between dysphagia and oesophageal neoplasia; haemoptysis and rectal bleeding had less strong associations and predictive values.

More research in this area, using well characterised, large patient populations, should further refine the implications of alarm symptoms and, in particular, use more detailed description of the symptoms themselves and of patients' characteristics to determine the urgency with which investigations and specialist referral need to be pursued.

Contributors: RJ had the original idea for the study, which was designed by all authors. MCG, RL, and JC extracted and analysed data. RJ drafted the paper, and all authors contributed to the final version. MCG is the guarantor. Funding: Internal funds, Division of Health and Social Care Research, King's College London

Competing interests: None declared.

Ethical approval: Scientific and Ethical Advisory Group of the general practice research database (protocol number 785R).

1 O'Donnell CA. Variation in GP referral rates: what can we learn from the literature? Fam Pract 2000;17:462-71.

2 O'Sullivan C, Omar RZ, Ambler G, Majeed A. Case-mix and variation in specialist referrals in general practice. Br J Gen Pract 2005;55:529-33.

3 Department of Health. Referral guidelines for suspected cancer London: DH, 2000.

4 Jones R, Rubin G, Hungin P. Is the two week rule for cancer referrals working? BMJ 2001;322:1555-6.

5 National Institute for Health and Clinical Excellence. Referral guidelines for suspected cancer. London: NICE, 2005.

6 Marinker M. Looking and leaping. In: Marinker M, Peckham M, eds. Clinical futures. London: BMJ Books, 1998.

7 Dixon AS. 'There's a lot of it about': clinical strategies in family practice. J Roy Coll Gen Pract 1986;36:468-71.

8 Buntinx F, Wauters $\mathrm{H}$. The diagnostic value of macroscopic haematuria in diagnosing urological cancers: a meta-analysis. Fam Pract 1997;14:63-8.

9 Bruyninckx R, Buntinx F, Aertgeerts B, Van Casteren V. The diagnostic value of macroscopic haematuria for the diagnosis of urological cancer in general practice. BrJ Gen Pract 2003;53:31-5.

10 Summerton N, Mann S, Rigby AS, Ashley J, Palmer S, Hetherington JW. Patients with new onset haematuria: assessing the discriminant value of clinical information in relation to urological malignancies. BrJ Gen Pract 2002;52:284-9.

11 Hamilton W, Sharp DJ, Peters TJ, Round AP. Clinical features of prostate cancer before diagnosis: a population-based, case-control study. Br J Gen Pract 2006;56:756-62.

12 Kapoor N, Bassi A, Sturgess R, Bodger K. Predictive value of alarm features in a rapid access upper gastrointestinal cancer service. Gut 2005;54:40-5.

13 Varadarajulu S, Eloubeidi MA, Patel RS, Mulcahy HE, Barkun A, Jowell P, et al. The yield and the predictors of esophageal pathology when upper endoscopy is used for the initial evaluation of dysphagia. Gastrointest Endosc 2005;61:804-8.

14 Meineche-Schmidt V, Jorgensen T. 'Alarm symptoms' in patients with dyspepsia: a three-year prospective study from general practice. Scand J Gastroenterol 2002;37:999-1007.

15 Vakil N, Moayyedi P, Fennerty MB, Talley NJ. Limited value of alarm features in the diagnosis of upper gastrointestinal malignancy: systematic review and meta-analysis. Gastroenterology 2006;131:390-401.

16 Hamilton W, Sharp D. Diagnosis of lung cancer in primary care: a structured review. Fam Pract 2004;21:605-11.

17 Fidan A, Ozdogan S, Oruc O, Salepci B, Ocal Z, Caglayan B. Hemoptysis: a retrospective analysis of 108 cases. Respir Med 2002;96:677-80.

18 Hirshberg B, Biran I, Glazer M, Kramer MR. Hemoptysis: etiology, evaluation, and outcome in a tertiary referral hospital. Chest 1997;112:440-4.

19 Hamilton W, Peters TJ, Round A, Sharp D. What are the clinical features of lung cancer before the diagnosis is made? A population based case-control study. Thorax 2005;60b:1059-65.

20 Crosland A, Jones R. Rectal bleeding: prevalence and consultation behaviour. BMJ 1995;311:486-8.

21 Chapuis PH, Goulston KJ, Dent OF, Tait AD. Predictive value of rectal bleeding in screening for rectal and sigmoid polyps. $B M$ J 1985;290:1546-8.

22 Nakama H, Kayano T, Katsuura T, Kamigaito T, Shimada S, Nishikawa N, et al. Comparison of predictive value for colorectal cancer in subjects with and without rectal bleeding. HepatoGastroenterology 1999;46:1730-2.

23 Ferraris R, Senore C, Fracchia M, Sciallero S, Bonelli L, Atkin WS, et al. Predictive value of rectal bleeding for distal colonic neoplastic lesions in a screened population. Eur J Cancer 2004;40:245-52.

24 Hamilton W, Sharp D. Diagnosis of colorectal cancer in primary care: the evidence base for guidelines. Fam Pract 2004;21:99-106.

25 Wauters H, Van Casteren V, Buntinx F. Rectal bleeding and colorectal cancer in general practice: diagnostic study. BMJ 2000;321:998-9.

26 Lawrenson R, Logie J, Marks C. Risk of colorectal cancer in general practice patients presenting with rectal bleeding, change in bowel habit or anaemia. Eur J Cancer Care 2006;15:267-71.

27 Hamilton W, Round A, Sharp D, Peters TJ. Clinical features of colorectal cancer before diagnosis: a population-based case-control study. Br J Cancer 2005;93:399-405.

28 Jick H, Jick SS, Derby LE. Validation of information recorded on general practitioner based computerised data resource in the United Kingdom. BMJ 1991;302:766-8.

29 Ellis BG. Thompson MR. Factors identifying higher risk rectal bleeding in general practice. BrJ Gen Pract 2005;55:949-55.

30 Jick SS, Kaye JA, Vasilakis-Scaramozza C, Garcia Rodriguez LA Ruigomez A, Meier CR, et al. Validity of the general practice research database. Pharmacotherapy 2003;23:686-9.

31 Dent J, Brun J, Fendrick AM, Fennerty MB, Janssens J, Kahrilas PJ, et al. An evidence based appraisal of reflux disease management: the Genval workshop report. Gut 1999;44(suppl 2):S1-16.

32 Vakil N, van Zanten SV, Kahrilas P, Dent J, Jones R, Global Consensus Group. The Montreal definition and classification of gastroesophageal reflux disease: a global evidence-based consensus. Am J Gastroenterol 2006;101:1900-20.

33 Du Toit J, Hamilton W, Barraclough K. Risk in primary care of colorectal cancer from new onset rectal bleeding: 10 year prospective study. BMJ 2006;333:69-70.

34 Fitjen G, Starmans R, Muris J, Schouten H, Blijham GH, Knottnerus JA Predictive value of signs and symptoms for colorectal cancer in patients with rectal bleeding in general practice. Fam Pract 1995;12:279-86.

Accepted: 20 March 2007 